\title{
Risk Factors for Osteoporosis and Fractures in Postmenopausal Women Between 50 and 65 Years of Age in a Primary Care Setting in Spain: A Questionnaire
}

\author{
Maria Luz Rentero,, , Cristina Carbonell ${ }^{2}$, Marta Casillas ${ }^{1}$, Milagros González Béjar ${ }^{3}$ and \\ Rafael Berenguer ${ }^{4}$ for the FARO Study Investigators
}

\author{
${ }^{I}$ Clinical Research Department, Lilly, SA, Madrid, Spain \\ ${ }^{2}$ ABS Via Roma, Barcelona, Spain \\ ${ }^{3}$ C.S. Montesa, Madrid, Spain \\ ${ }^{4}$ C.S. Algemesi, Valencia, Spain
}

\begin{abstract}
Introduction: Osteoporosis (OP) is a major, highly prevalent health problem and osteoporosis-related fractures account for high morbidity and mortality. Therefore, prevention and early detection of osteoporosis should strive to substantially reduce this risk of fracture.

Objective: The present observational, descriptive, cross-sectional study sought to assess the prevalence of risk factors for osteoporosis and fractures in a large sample of postmenopausal women aged 50 to 65 years attending Primary Care facilities in Spain.

Methods: We recruited 4,960 women, at 96 Primary Care centers. Demographic and anthropometrical data, as well as information regarding risk factors for OP were collected using a questionnaire.

Results: The prevalence rates for the major osteoporosis risk factors in our population were: low calcium intake, $43 \%$; benzodiazepine use, $35.1 \%$, and height loss, $30.1 \%$. Other relatively prevalent factors include: having suffered at least one fall during the preceding year; positive family history of falls (particularly on the mother's side), smoking, kyphosis, presence of any disease affecting bone metabolism, personal history of falls, and inability to rise from a chair without using one's arms. The least frequent factors were weight loss of greater than $10 \%$ over the preceding 10 years and problems in sensory perception that affect patient's ability to walk.

Conclusions: The main risk factors for osteoporosis in women 50-65 years of age are low calcium intake, use of benzodiazepines, and observed loss of height. Our results may help physicians to identify groups at risk for OP and fractures at early stages and consequently, optimize prevention and early diagnosis of osteoporosis in postmenopausal women.
\end{abstract}

Keywords: Postmenopausal women, risk factors, osteoporosis, primary health care.

\section{INTRODUCTION}

Osteoporosis (OP) is a highly prevalent disease particularly in postmenopausal women, characterized by decreased bone density resulting in increased susceptibility to fracture $[1,2]$. The clinical relevance of $\mathrm{OP}$ is derived not only from the increase in morbidity and mortality, but also the pain, physical impairment, and loss of functional ability that have an important impact on patients' quality of life. It also entails significant cost to society: hospitalization costs are increased as are medical tests, length of stay in nursing homes and consulting rooms, as well as the costs associated with patients' diminished activity [3-5]. According to the World Health Organization (WHO), 30\% of Caucasian

\footnotetext{
*Address correspondence to this author at the Clinical Research Department, Lilly, SA, Avenida de la Industria, 30 Alcobendas E-28108, Madrid, Spain; Tel: +34916635000; Fax: +34916635231; E-mail: rentero_mariluz@lilly.com
}

women over the age of 50 suffer from OP versus $8 \%$ in males [6]. In Spain, $17.2 \%$ of females aged 50-60 years may suffer from OP. The percentage of affected women rises to $40 \%$ between $60-70$ years of age [7].

$\mathrm{OP}$ is a chronic disease requiring chronic treatment. However, as this condition produces little or no symptoms, patients go undiagnosed until a fracture occurs and the osteoporosis is more severe. Hence, disease prevention and early diagnosis are particularly important. Nevertheless, effective diagnostic tools are currently not available to assist Primary Care physicians in detecting individuals at risk for developing $\mathrm{OP}$ and associated fractures in the future. Identifying OP risk factors will aid Primary Care physicians in selecting patients for evaluation and intervention.

That is why it is important to assess not only the risk factors associated with osteoporosis per se, which are fairly well-known, but also their prevalence in the general population. Several studies have shown that there are many 
risk factors that need to be taken into account: age, early menopause, history of previous fractures, family history, being underweight or treatment. The prevalence of these factors has been analyzed [8-10] however, most of these studies have been conducted in women over the age of 65 years.

Consequently, little information is available on the most prevalent risk factors for OP in postmenopausal women aged $50-65[11,12]$ which is where OP prevention schemes should be focused on substantially decreasing the incidence of $\mathrm{OP}$ and fractures.

This study sought to assess the prevalence of risk factors for osteoporosis and fractures in a large sample of postmenopausal women aged 50 to 65 years cared for at Primary Care facilities in Spain.

\section{MATERIALS AND METHODS}

\section{Study Design}

An observational, cross-sectional, descriptive study was designed to analyze the prevalence of different OP risk factors. The study was conducted at Primary Care centers belonging to the public healthcare system in Spain. The distribution of sites (100 sites planned) across the Spanish geography and sample size (50 patients per site) was calculated on the basis the number of patients with this specific age according the 1998 Census by quotes and geographic distribution to achieve a truly representative sample.

Dedication to the study was reimbursed according to European Medicines Evaluation Agency (EMEA) guidelines for studies of this kind [13]. The protocol was approved by an independent review board.

\section{Patients and Procedures}

Postmenopausal women with ages between 50 and 65 years attending a routine visit with any of the participating physicians were invited to participate in the study, regardless of the reason for consultation. A signed authorization for the collection and use of clinical data in accordance with standing regulations regarding personal data protection was obtained from all subjects prior to enrollment. Patients participating in any other clinical study of OP drug treatment were excluded.

Demographic, anthropometric, and risk factors for OP and fracture data were recorded for patients included in the study using a 14-item questionnaire administered by physician. The questionnaire included the following information: personal data (date of birth, age at menarche, age at onset of menopause, type of menopause, number of children), physical examination (weight, height, pulse), osteoporosis and fracture risk factors (weight loss greater than $10 \%$ in the last 10 years or if the loss it has compared with in weight that it had to the 35 years, loss of height, kyphosis, disturbances of sensory perception, number of falls in the previous year, ability to stand up from a chair unaided), patient life style factors (dietary consumption of dairy products in mg, physical activity, cigarette smoking), personal history of previous fragility fractures (excluding trauma fractures), family history of osteoporotic fracture (father, mother, or sisters), prior and present use of drugs affecting bone metabolism (bisphosphonates, HRT, calcitonins, calcium and vitamin $\mathrm{D}$, raloxifene, tibolone), drugs that increase the risk of osteoporosis or fractures (anticonvulsants, thyroid hormones, oral and inhaled glucocorticoids, oral anticoagulants, benzodiazepines, antiarrhythmics, oral insulins, hypoglycemics, lithium), and disorders that affect bone metabolism and increase the risk of falls (chronic liver disease, Cushing's syndrome, hyperparathyroidism, stroke, malabsorption syndromes, secondary amenorrhea lasting at least one year, obstructive pulmonary disease, rheumatoid arthritis, urolithiasis, Parkinson's disease, hyperthyroidism, gastrectomy, and type I diabetes).

\section{Statistics}

Quantitative variables were described in terms of mean and median values, as well as typical deviation, first and third quartile, and range (maximum and minimum values). They are analyzed using an ANOVA model. Qualitative variables were described by frequency and percentage and analyzed using the Chi square test or, if not applicable, by means of Fisher's exact test. The 95\% confidence intervals are used for all variables.

Patients were included on an intention-to-treat (ITT) basis.

\section{RESULTS}

A total of 4960 women were screened for the study over a 10-month period (July 2002-April 2003) at 96 primary care centers. All patients signed the inform consent. Sixty-two patients were excluded because they did not meet inclusion/ exclusion criteria (mainly age). As a result, 4898 patients were finally included in the analysis and distributed into three age subgroups: $39 \%$ of the patients were $50-55$ years of age $(n=1905), 28 \%$ were $56-59(n=1378)$, and $33 \%$ were 60 $65(\mathrm{n}=1615)$.

General characteristics $(\mathrm{N}=4898)$ are summarized in Table 1. No significant differences were observed between age groups for physical characteristics on the whole; we therefore examined more detailed data for the entire group. Mean age at menarche was 12.87 (SD: 1.6), slightly higher in the 60-65 year age group (13.6). Mean age at onset of menopause was 48.5 (SD: 4.5). Menopause was natural in $84.9 \%$ of the subjects. The data collected from the physical examination yielded a mean weight of $69.7 \mathrm{~kg}$ and mean height of $157 \mathrm{~cm}$. Mean body mass index was $28.3 \mathrm{~kg} / \mathrm{m}^{2}$ indicating that our population is somewhat overweight.

The prevalence of risk factors is detailed in Table 2. According to the data obtained, factors with a prevalence rate greater than $30 \%$ are: low calcium intake $(\leq 600 \mathrm{mg} /$ day, measured by dairy product intake), $43 \%$; use of drugs that can influence bone metabolism and/ or increase the risk of fracture, $35.1 \%$; lack of physical activity (defined as no intentional physical activity declared by the patient), $31.8 \%$, and observed height loss throughout the patient's life, $30.4 \%$.

Other OP and fracture risk factors detected in our population included: having suffered at least one fall over the preceding year $(22.8 \%)$. This percentage increased with age: $17.7 \%$ in the $50-55$ year group; $23.2 \%$ in the $56-59$ year old group, and $28.7 \%$ in the women aged $60-65$ years. 
Table 1. General Characteristics $(\mathrm{N}=\mathbf{4 8 9 8})$

\begin{tabular}{|c|c|c|c|c|}
\hline & Mean & SD & $95 \% \mathrm{CI}$ & Median \\
\hline Age at menarche (years) & 12.87 & 1.6 & $12.8-12.9$ & 13 \\
\hline Age at onset of menopause (years) & 48.49 & 4.5 & 48.4-48.6 & 49 \\
\hline Number of children & 2.46 & 1.5 & $2.4-2.5$ & 2 \\
\hline Weight $(\mathrm{kg})$ & 69.7 & 11.8 & $69.4-70.0$ & 68.5 \\
\hline Height $(\mathrm{cm})$ & 157.08 & 6.6 & $156.9-157.2$ & 157 \\
\hline Body Mass Index & 28.31 & 4.9 & $28.2-28.5$ & 27.7 \\
\hline Number of falls in the preceding year & 1.96 & 2.86 & $1.79-2.13$ & 1 \\
\hline Number of hours of physical activity/ week & 3.9 & 4.9 & $3.7-4.1$ & 3 \\
\hline
\end{tabular}

Table 2. Prevalence of OP and Fracture Risk Factors $(\mathrm{N}=4898)$

\begin{tabular}{|c|c|c|c|c|c|}
\hline & $\begin{array}{c}\text { 50-55 Years } \\
\mathrm{N}=1905 \\
(\%)\end{array}$ & $\begin{array}{c}\text { 56-59 Years } \\
\mathrm{N}=1378 \\
(\%)\end{array}$ & $\begin{array}{c}\text { 60-65 Years } \\
\text { N=1615 } \\
(\%)\end{array}$ & $\begin{array}{c}\text { Total } \\
\text { N=4898 } \\
(\%)\end{array}$ & $\begin{array}{c}\text { Chi-Square } \\
\text { p-Value }\end{array}$ \\
\hline Dairy product intake ( $\leq 600 \mathrm{mg} /$ day) & $773(40.6)$ & $600(43.5)$ & $738(45.7)$ & $2111(43.1)$ & 0.0087 \\
\hline Observed height loss & $448(23.5)$ & $410(29.8)$ & $632(39.1)$ & $1490(30.4)$ & $<0.0001$ \\
\hline Observed weight loss $\geq 10 \%$ in 10 years & $141(7.5)$ & $111(8.1)$ & $145(9.0)$ & $398(8.1)$ & 0.2971 \\
\hline Patients with at least one fall in the preceding year & $337(17.7)$ & $319(23.2)$ & $463(28.7)$ & $1119(22.8)$ & $<0.0001$ \\
\hline Presence of kyphosis & $266(14.0)$ & $255(18.5)$ & $395(24.5)$ & $916(18.7)$ & $<0.0001$ \\
\hline Inability to rise from a chair without using one's arms & $166(8.7)$ & $128(9.3)$ & $196(12.1)$ & $490(10.0)$ & $0.0009^{*}$ \\
\hline $\begin{array}{l}\text { Problems in sensory perception affecting patient's ability to } \\
\text { walk }\end{array}$ & $104(5.5)$ & $91(6.6)$ & $146(9.0)$ & $341(7.0)$ & $<0.0001 *$ \\
\hline Current and past smoking status & $610(32.0)$ & $251(18.2)$ & $212(13.1)$ & $1163(21.9)$ & $<0.0001^{*}$ \\
\hline Lack of physical activity & $601(31.5)$ & $421(30.6)$ & $534(33.1)$ & $1556(31.8)$ & 0.334 \\
\hline Personal history of osteoporotic fracture & $136(7.1)$ & $123(8.9)$ & $246(15.2)$ & $505(10.3)$ & $<0.0001 *$ \\
\hline Family history of osteoporotic fracture & $415(21.8)$ & $300(21.8)$ & $379(23.5)$ & $1094(22.3)$ & 0.1749 \\
\hline Mother & $(18.2)$ & (17) & $(17.2)$ & $(17.5)$ & 0.5869 \\
\hline $\begin{array}{l}\text { Use of drugs that can influence bone metabolism and/ or } \\
\text { increase risk of fracture: current or past }\end{array}$ & $570(29.9)$ & $506(36.7)$ & $642(39.8)$ & $1718(35.1)$ & $<0.05$ \\
\hline $\begin{array}{l}\text { Presence of bone metabolism disorder or disease that increases } \\
\text { risk of falls }\end{array}$ & $194(10.2)$ & $145(10.5)$ & $246(15.2)$ & $585(11.9)$ & $<0.05$ \\
\hline
\end{tabular}

${ }^{*} \mathrm{CMH}$ (Cochran-Mantel-Haenszel).

Insofar as the prevalence of previous osteoporotic fractures is concerned (see Table 3), 10\% of all patients had had at least one fracture in the past with the forearm the most common fracture site $(35 \%)$. Twenty-two percent of the patients had a positive family history of osteoporotic fracture(s) $(22.3 \%)$, predominantly on their mother's side $(17.5 \%)$.

Other factors were presence of kyphosis (18.7\%), observed weight loss greater than $10 \%$ over the previous 10 years $(8 \%)$, inability to rise from a chair without using one's arms $(10 \%)$, problems in sensory perception affecting the patient's ability to walk (from $5.5 \%$ to $9 \%$ depending on age group), and lifestyle-related factors such as, current or past smoking (21\%).

Strikingly, $30.2 \%$ of the study subjects were taking any medication for OP (Table 4) and of them, 8.1\% were only taking calcium and/or vitamin $\mathrm{D}$.
Table 3. Site of Prior Osteoporotic Fracture $(n=505)$

\begin{tabular}{|l|c|c|}
\hline & Number of Fractures & \%* \\
\hline \hline Forearm & 179 & 3.65 \\
\hline Foot & 103 & 2.10 \\
\hline Leg & 89 & 1.81 \\
\hline Vertebra & 48 & 1.0 \\
\hline Humerus & 30 & 0.6 \\
\hline Sternum/ Ribs & 17 & 0.34 \\
\hline Hip & 16 & 0.32 \\
\hline Clavicle/ Scapula & 10 & 0.2 \\
\hline Sacrum/ Coccyx & 9 & 0.18 \\
\hline
\end{tabular}


As mentioned previously, 35\% of the patients were taking drugs that could influence bone metabolism and/ or increase the risk of fracture (Table 4), the most frequent of which were: benzodiazepines $(36 \%)$, thyroid hormones (5.5\%), and oral antidiabetic agents $(4.2 \%)$.

Table 4. Drugs to Treat Bone Metabolism Disorder and those that can Affect Bone Metabolism

\begin{tabular}{|l|c|}
\hline & \%* $^{*}$ \\
\hline \hline Drugs to treat bone metabolism disorder: current use \\
\hline Calcium & 16.9 \\
\hline Hormone replacement therapy & 7.4 \\
\hline Vitamin D & 7.2 \\
\hline Raloxifene & 7.3 \\
\hline Biphosphonates & 4.6 \\
\hline Calcitonin & 1.3 \\
\hline Tibolone & 2.2 \\
\hline Drugs that can affect bone metabolism: past or current use \\
\hline Benzodiazepines & 22.6 \\
\hline Thyroid hormones & 5.5 \\
\hline Hypoglycemics & 4.2 \\
\hline Inhaled glucocorticoids & 2.8 \\
\hline Oral glucocorticoids & 2.6 \\
\hline Anticoagulants & 1.9 \\
\hline Antiarrythmics & 1.8 \\
\hline Insulins & 1.2 \\
\hline Anticonvulsants & 0.3 \\
\hline Lithium & \\
\hline Calculated from the total study population N=4898. & 1.2 \\
\hline
\end{tabular}

Additionally, $11 \%$ of the participants were suffering from a bone metabolism disorder or a disease that increases the risk of falls; the most common of them were: urolithiasis in $3.7 \%$ and hypothyroidism and chronic pulmonary obstructive disease, both in $1.7 \%$ of the patients and reumatoid arthritis in $1.5 \%$ of patients.

\section{DISCUSSION}

The present naturalistic study reveals the prevalence of various risk factors in postmenopausal women aged 50 to 65 years visiting their physician for routine consultation.

From our results, the most prevalent OP and fracture risk factors (over 30\%) are low calcium intake (less than $600 \mathrm{mg}$ / day), use of drugs that affect bone metabolism (mainly benzodiazepines), and observed height loss, followed by lack of any physical activity. There is another important group of moderately prevalent factors (10-23\%) including: having had at least one fall in the last year; family history of falls (especially on the mother's side), cigarette smoking, kyphosis, presence of a disorder affecting bone metabolism, personal history of falls, and inability to stand up from a chair without using one's arms. The least frequent risk factors observed were weight loss greater than $10 \%$ in the last 10 years and problems in sensory perception that affect patient's ability to walk.

When relating the prevalence of the different risk factors found in our study with the relative importance of those factors with respect to osteoporosis as assessed in a published review [14], we have detected differences between both concepts. Some of the factors considered as high risk had a low prevalence; hence, their final importance may in fact be relative.

According to our study, with the exception of age, considered to be a high risk factor when over 70 years and therefore excluded from our study population, there is only one high risk factor that also displayed a high prevalence rate - physical inactivity. This is consistent with the findings of a retrospective review of the prevalence of risk factors in a general female population aged 50 years and older [15] and also with the improvements in dynamic balance and strength, both important determinants of risk for falls in a communitybased exercise program conducted in a randomized control trial [16]. Van der Voort et al. also reports that practicing sports, even in the past, exhibited a slightly positive relationship with the patients' fractures [17].

Other important high risk factors that were identified are personal history of osteoporotic fracture $[18,19]$ and weight loss [14]. Nevertheless, both of them had a prevalence rate of approximately $10 \%$ in our study, which seems reasonable compared with the older population, due to the shorter time of deterioration given the fact that our population was younger.

The personal history of fracture reported in older women ranged from $39.2 \%$ to $24.3 \%$ [8, 20, 21]. The figure from a Spanish population was a lower (20.1\%) [10], perhaps due to the lower incidence of osteoporotic fracture in the Spanish population versus the USA [22]. Nevertheless, data from our study yield a much lower figure of $10.3 \%$; this is in line with studies in younger populations (patients over the age of 45 years) that present rates that range from 8 to $10 \%$ [23-25]. Weight loss had been considered to be the best predictor of low bone mineral density in elderly women [26], however it seems that it is less important in women under 65 years of age.

On the other hand, some of the moderate risk factors [14] were highly prevalent in our study population. We have established that low calcium intake was the most prevalent factor found in the study (43\%). This deficiency was not compensated with calcium supplements as only $16.9 \%$ of study population was taken this type of supplements. Remarkably, only $22,1 \%$ of patients were taking specific medication for OP.

A positive family history of osteoporotic fracture, particularly on the mother's side, was also highly prevalent in our study population, $22.3 \%$, albeit lower than data published in the literature that has been cited at around $30 \%$ $[23,27]$. This seems reasonable since our population was younger, so that their families (mainly mother and sisters) were also younger and had less osteoporosis fractures. Once again, this difference can be attributed the lower incidence of osteoporotic fracture in the Spanish population versus the USA [22]. 
Another well-known risk factor [28], smoking, was present in $22 \%$ of our study population. Current and past cigarette smoking is the only factor that differed significantly in terms of prevalence between the different age groups in our study. The highest prevalence for this factor, $32.1 \%$, was found in the youngest group (50-55 years) compared to the other two groups: $18.2 \%$ in the $55-60$ year-old group and $13.1 \%$ in the oldest age group (60-65 years). This difference is easily accounted for if we consider lifestyle changes and increased rates of smoking among the female population in Spain. It is also consistent with the results obtained in the ESOPO study in premenopausal women [29], which concluded that bone stiffness was negatively correlated to age and number of cigarettes and positively related to body weight, body weight at age 25 , height, and estimated daily calcium intake in this special population. Nevertheless, data regarding smoking is highly variable in the literature because of the idiosyncratic, sociological influence on this range [10].

Similarly, the use of drugs that can influence bone metabolism and/ or increase risk of fracture is also conditioned by sociological idiosyncrasies. Different clinical and prescription habits can explain the high prevalence of benzodiazepine-based treatment that was consistent with another Spanish study carried out in an older patient population [10] but significantly higher than other published studies reporting data of approximately $9 \%[20,21]$. This is also the case with thyroid hormone use - our study detected a $5.5 \%$ rate of thyroid hormone use; a 3.5\% rate is reported in the older Spanish population and between 11-18\% in other literature reports $[20,24,30]$.

This study has the inherent limitations owing to its naturalistic design. For instance, we cannot exclude the possibility of recall bias due to seft-report of information regarding risk factors and history of previous fractures, despite the evidence indicating that self-report is highly accurate $[31,32]$. Another limitation is that patients included into the study were those attending a routine visit to a Primary Care centers and are not general population. This inconvenience was minimized by selecting patients by quotes per age and geographic distribution according the 1998 Census to achieve a truly representative sample and offers them the study regardless of the reason for consultation. It is also noticeable that the prevalence of the risk factors identified may not reflect the actual importance of their contribution to osteoporosis, being for example of low frequent but high impact on the osteoporosis disease.

As we have already seen in the discussion, it is highly subject to idiosyncratic influences (for example: drug prescription, smoking habits...), but there are other general factors whose prevalence are of great overall relevance.

This is the first study to show the prevalence of risk factors for $\mathrm{OP}$ and fractures in a large sample of postmenopausal patients aged 50-65 years in a Primary Care setting. In contrast with the $\geq 65$ years series [8-10] there are some factors that are found to be more prevalent in our population: low calcium intake (including low percentage of patients taking calcium or vitamin D), smoking habits, and family history of osteoporosis. With age, other factors take on greater relevance, such as personal history of osteoporotic fracture, other concomitant diseases, and the use of drugs that can influence bone metabolism, weight loss, etc... [33, 34].

Taking into account that age itself is a clearly defined risk factor, it seems evident that other factors are of different relevance depending on patients' age; it will therefore be extremely valuable to have data about different factors at different ages.

Identifying prevalence factors in this younger population is especially important because, while certain risk factors such as age and gender can obviously not be modified, there are other risk factors such as calcium or vitamin D deficiency that can, at least theoretically, be changed [35].

\section{CONCLUSIONS}

As we have pointed out, the relevance of the different risk factors for osteoporosis and fractures in postmenopausal women factors are clearly dependence on patients' age. According our results, the main factors for osteoporosis in postmenopausal women 50-65 years of age in the Primary Care setting are low calcium intake, benzodiazepine use, and observed height loss. Our results may help physicians to identify groups of patients who are at risk for OP and fracture at early stages and subsequently optimize prevention and/ or early diagnose of osteoporosis in postmenopausal women.

\section{ACKNOWLEDGEMENTS}

The authors would like to thank all the Primary Care centers that participated in this study, as well as the patients who agreed to participate, provided consent for the use of part of their clinical data, and went to an additional visit to fulfill study procedures.

\section{CONFLICT OF INTEREST}

Authors Maria Luz Rentero, and Marta Casillas are fulltime employees of Lilly S.A., Avda. de la Industria, 30. 28108 Alcobendas - Spain.

\section{REFERENCES}

[1] U.S. Department of Health and Human Services. Bone health and osteoporosis: A report of the Surgeon General. Rockville, MD, U.S. Department of Health and Human Services, Office of the Surgeon General; 2004.

[2] Assessment of fracture risk and its application to screening for postmenopausal osteoporosis. Report of a WHO Study Group. (WHO Technical Report Series, No. 843). World Health Organization, Geneva, 1994.

[3] Ray NF, Chan JK, Thamer M, Melton LJ 3rd. Medical expenditures for the treatment of osteoporotic fractures in the United States in 1995: report from the National Osteoporosis Foundation. J Bone Miner Res 1997; 12(1): 24-35.

[4] Lippuner K, Golder M, Greiner R. Epidemiology and direct medical costs of osteoporotic fractures in men and women in Switzerland. Osteoporos Int 2005; 16 (Suppl 2): S8-S17.

[5] Maravic M, Le Bihan C, Landais P, Fardellone P. Incidence and cost of osteoporotic fractures in France during 2001. A methodological approach by the national hospital database. Osteoporos Int 2005; 16(12): 1475-80.

[6] Prevention and Management of Osteoporosis: Report of a WHO Scientific Group (WHOTechnical Report Series, No. 921) World Health Organization; Geneva. 2003.

[7] Díez Curiel M, García JJ, Carrasco JL, et al. Prevalencia de osteoporosis determinada por densitometría en la población femenina española. Med Clin 2001; 116: 86-8.

[8] McGrother CW, Donaldson MM, Clayton D, Abrams KR, Clarke M. Evaluation of a hip fracture risk score for assessing elderly 
women. The melton osteporotic fracture (MOF) study. Osteo-poros Int 2002; 13 (1): 89-96.

[9] Von Mühlen D, Visby Lunde A, Barrett-Connor E, Bettencourt R. Evaluation of the simple calculated osteoporosis risk estimation (SCORE) in older Caucasian women. The Rancho Bernardo study. Osteoporos Int 1999; 10 (1): 79-84.

[10] González-Macías J, Marín F, Vila J, et al. Prevalencia de factores de riesgo de osteoporosis y fracturas osteoporóticas en una serie de 5.195 mujeres mayores de 65 años. Med Clin 2004; 123(3): 85-9.

[11] Weinstein L, Ullery B, Bourguignon C. A simple system to determine who needs osteoporosis screening. Obstet Gynecol 1999; 93(5 Part 1): 757-60.

[12] Jönsson B. Targeting high-risk populations. Osteoporos Int 1998; 8 (Suppl 1): S13-S16.

[13] EMEA. Notice to marketing authorization holders. Pharmacovigilance guidelines. Available from http: //www.emea.europa.eu/ pdfs/human/phvwp/161801en.pdf (Accessed date: 2008 Oct 17).

[14] Espallargues M, Sampietro-Colom L, Estrada MD, et al. Identifying bone-mass-related risk factors for fracture to guide bone densitometry measurements: a systematic review of the literature. Osteoporos Int 2001; 12(10): 811-22.

[15] Kirk JK, Spangler JG, Celestino FS. Prevalence of osteoporosis risk factors and treatment among women aged 50 years and older. Pharmacotherapy 2000; 20(4): 405-9.

[16] Carter ND, Khan KM, McKay HA, et al. Community-based exercise program reduces risk factors for falls in 65- to 75-year-old women with osteoporosis: randomized controlled trial. CMAJ 2002; 167(9): 997-1004. Erratum in: CMAJ 2003; 168(2): 152.

[17] van der Voort DJ, Geusens PP, Dinant GJ. Risk factors for osteoporosis related to their outcome: fractures. Osteoporos Int 2001; 12(8): 630-8.

[18] van Geel AC, Geusens PP, Nagtzaam IF, et al. Timing and risk factors for clinical fractures among postmenopausal women: A 5year prospective study. BMC Med 2006; 4: 24.

[19] Leslie WD, Metge C, Ward L. Contribution of clinical risk factors to bone density-based absolute fracture risk assessment in postmenopausal women. Osteoporos Int 2003; 14(4): 334-8.

[20] Cummings SR, Nevitt MC, Browner WS, et al. Risk factors for hip fracture in white women. N Engl J Med 1995; 332: 767-73.

[21] Black DM, Steinbuch M, Palermo L, et al. An assessment tool for predicting fracture risk in postmenopausal women. Osteoporos Int 2001; 12(7): 519-28.

[22] Olmos JM, Martínez J, García J, Matorras P, Moreno JJ, GonzálezMacías J. Incidencia de fractura de cadera en Cantabria. Med Clin 1992; 99: 729-31.
[23] Cadarette SM, Jaglal SB, Murray TM, et al. Evaluation of decision rules for referring women for bone densitometry by dual-energy $\mathrm{X}$ ray absorptiometry. JAMA 2001; 286(1): 57-63.

[24] Siris ES, Miller PD, Barrett-Connor E, et al. Identification and fracture outcomes of undiagnosed low bone mineral density in postmenopausal women. Results from the National Osteoporosis Risk Assessment. JAMA 2001; 286 (22): 2815-22.

[25] Miller PD, Siris ES, Barrett-Connor E, et al. Prediction of fracture risk in postmenopausal women with peripheral bone densitometry: Evidence from the National Osteoporosis Risk Assessment. J Bone Miner Res 2002; 17(12): 2222-30.

[26] Dargent-Molina P, Poitiers F, Breart G, for the EPIDOS group. In Elderly Women Weight is the Best Predictor of a Very Low Bone Mineral Density: Evidence from the EPIDOS Study. Osteoporos Int 2000; 11(10): 881-8.

[27] Grainge MJ, Coupland CAC, Cliffe SJ, Chilvers CED, Hosking DJ Association between a family history of fractures and bone mineral density in early postmenopausal women. Bone 1999; 24(5): 507 12.

[28] Ill PO, Alexandre C. Tobacco as risk factor of osteoporosis, myth or reality? Rev Rhum Ed Fr 1993; 60(4): 280-6.

[29] Adami S, Giannini S, Giorgino R, et al. Effect of age, weight and lifestyle factors on calcaneal quantitative ultrasound in premenopausal women: the ESOPO study. Calcif Tissue Int 2004; 74(4): 317-2

[30] Cauley JA, Robbins J, Chen Z, et al. Effects of estrogen plus progestin on risk of fracture and bone mineral density. The Women's Health Initiative randomised trial. JAMA 2003; 290(13): 1729-38.

[31] Ismail AA, O'Neill TW, Cockerill W, et al. Validity of self-report of fractures: results from a prospective study in men and women across Europe. EPOS Study Group. European Prospective Osteoporosis Study Group. Osteoporos Int 2000; 11(3): 248-54.

[32] Ivers RQ, Cumming RG, Mitchell P, Peduto AJ. The accuracy of self-reported fractures in older people. J Clin Epidemiol 2002; 55(5): 452-7.

[33] Adami S, Giannini S, Giorgino R, et al. The effect of age, weight, and lifestyle factors on calcaneal quantitative ultrasound: the ESOPO study. Osteoporos Int 2003; 14(3): 198-207.

[34] Papaioannou A, Joseph L, Ioannidis G, et al. Risk factors associated with incident clinical vertebral and nonvertebral fractures in postmenopausal women: the Canadian Multicentre Osteoporosis Study (CaMos). Osteoporos Int 2005; 16(5): 568-78.

[35] Ross PD. Risk factors for osteoporotic fracture. Endocrinol Metab Clin North Am 1998; 27(2): 289-301.

(C) Rentero et al.; Licensee Bentham Open.

This is an open access article licensed under the terms of the Creative Commons Attribution Non-Commercial License (http://creativecommons.org/licenses/by$\mathrm{nc} / 3.0 /$ ) which permits unrestricted, non-commercial use, distribution and reproduction in any medium, provided the work is properly cited. 